\title{
Türkiye'nin Batısında Solunum Yolu Enfeksiyonu Geçiren Çocuklarda Alternatif Tedavi Uygulamaları
}

\author{
Alternative Treatment Applications in Children with Respiratory Tract Infections in the \\ West of Turkey
}

Naci Topaloğlu, Şule Yıldırım, Mustafa Tekin, Ayşegül Uludağ*, Kenan Özgen*

Çanakkale Onsekiz Mart Üniversitesi Tıp Fakültesi, Çocuk Sağlığı ve Hastalıkları Anabilim Dalı, Çanakkale, Türkiye

*Çanakkale Onsekiz Mart Üniversitesi Tıp Fakültesi, Aile Hekimliği Anabilim Dall, Çanakkale, Türkiye

Yazışma Adresi/Address for Correspondence Dr. Şule Yildrirm, Çanakkale Onsekiz Mart Üniversitesi Tip Fakültesi, Çocuk Sağlı̆ıı ve Hastalıkları Ana Bilim Dall, Çanakkale, Türkiye GSM: +905058280707 E-posta: sules/n@yahoo.com

Geliş Tarihi/Received: 29.11.2012 Kabul Tarihi/Accepted: 12.03.2013

(c) Güncel Pediatri Dergisi, Galenos Yaynnevi tarafindan basilmıştr.

(c) The Journal of Current Pediatrics, published by Galenos Publishing.

\section{ÖZET}

Giriş: Toplumlar arası farklılıklar ve uygulamalar ne olursa olsun her geçen gün alternatif tedavilere eğilimin artığı bilinmektedir. Bu çalışmada bölgemizde solunum yolu enfeksiyonu nedeniyle çocuklara uygulanan alternatif tedavilerin ve ailelerin bu tedaviler hakkındaki düşüncelerinin saptanması amaçlanmıştır.

Gereç ve Yöntem: Çalışmamıza Ekim 2011-Şubat 2012 tarihleri arasında Çanakkale Onsekiz Mart Üniversitesi Araștırma ve Uygulama Hastanesi Çocuk Sağlığı ve Hastalıkları Genel Polikliniğine; ateş, öksürük, boğaz ağrısı, hıııltı gibi şikâyetlerle başvurup üst veya alt solunum yolu enfeksiyonu tanısı alan 214 çocuk ve ebeveyni alındı.

Bulgular: Ebeveynlerin \%93,7'si değişen sıkıklarda ilaç dışı uygulamalardan faydalanmakta idi. Ailelerin alternatif uygulamaları \%62,7 ilaç tedavisinden önce, \%28,7 ilaçlarla birlikte, \%6,7 ilaçlarla cevap alınamazsa, \%1,9 hiç kullanmadıkları görüldü. En sık yapılan uygulamaların öksürüğü azaltmak için sade bal verilmesi $(\% 30,6)$ ve ateşi düşürmek için ılık duş uygulaması $(\% 48,1)$ olduğu belirlendi. Ailelerin bu uygulamalarla ilgili bilgi kaynakları \%69,4 oranında akrabalar ve aile bireyleri idi. Alternatif tedavi uygulamaları ile ilgili bilgi alınmak istenen kaynak olarak ise \%84,5 ile doktor ve hemşire gibi sağılık çalışanları gösterildi. Eğitim durumu ile ilaç dışı uygulama sıkığı arasında istatistiksel anlamlı ilişki saptandı. Ancak bilgi edinilmek istenen kaynak eğitim durumuna göre değişiklik göstermiyordu.

Sonuç: Çocuk sağlığı ve hastalıkları hekimlerinin ve hemşirelerinin alternatif tedaviler hakkında bilgi edinip ailelere doğru yaklaşımlar hakkında yardımcı olmaları gerektiğini düşünüyoruz. (Güncel Pediatri 2013; 11: 23-6)

Anahtar kelimeler: Alternatif tedavi, solunum yolu enfeksiyonu, çocuk

\section{SUMMARY}

Introduction: It is known that the trend toward alternative treatments is increasing each day regardless of the differences between communities. We aimed to detect alternative treatments in our region and to determine the thoughts of families about these treatments.

Materials and Methods: A total of 214 patients presenting to General Pediatrics Outpatient Clinics of Çanakkale Onsekiz Mart University Teaching and Research Hospital between October 2012 and February 2012 with fever, coughs, sore throat, wheezing and diagnosed as upper or lower respiratory tract infection and their parents are included in the study.

Results: A total of $93.7 \%$ of parents were using non-drug applications with varying frequencies. Alternative practices are being used prior to drug treatment (62.7\%), with drugs $(28.7 \%)$, when there is no response to drugs $(6.7 \%)$ or never $(1.9 \%)$. Most common used applications to reduce cough was to give pure honey $(30.6 \%)$ and the most common application to lower the fever was to use warm shower (48.1\%). Most common source of information for these applications was relatives and family members. It was shown that the most requested resources to get information were doctors, nurses and other health care professionals with $84.5 \%$. There was statistically significant correlation between educational status and frequency of usage of non-drug applications. However, requested source of information did not change according to the educational status. 
Conclusions: As a result we thought that doctors and nurses dealing with child health and disease should obtain information about alternative treatments and help the parents about logical managements. (Journal of Current Pediatrics 2013; 11: 23-6)

Key words: Alternative treatment, respiratory tract infection, child

\section{Giriş}

Tıp dışı alternatif uygulamalar genellikle doğu tıbbında sık olarak kullanılmaktadır. Alternatif tedavi yöntemleri bazen tıbbi tedavilere destek olması için, bazen ilaç tedavisine cevap alınamadığında bazen de sadece tek başına uygulanmaktadır. Alternatif uygulamalar az veya çok neredeyse tüm toplumlarda vardır. Ülkemizde de sıklığı değişmekle birlikte tüm bölgelerde uygulandığı görülmektedir. Amerika ve Avrupa ülkelerinden yapılan yayınlarda tıp dışı alternatif tedavi kullanımları erişkinlerde \%25-50, çocuklarda ise $\% 1,8-70$ oranlarında bildirilmektedir $(1,2)$.

Çocuklarda akut solunumyolu enfeksiyonlarının oldukça sık görüldüğü bilinmektedir. Genel çocuk polikliniklerine başvuran hastaların yaklaşı \%30-40'ını solunum yolu enfeksiyonu geçiren çocuklar oluşturmaktadır. Başvuruların çoğu da üst solunum yolu enfeksiyonlarıdır (ÜSYE). Otit, sinüzit, rinit, farenjit, tonsilit ve epiglottit erişkinlerde olduğu gibi çocuklarda da en sık görülen ÜSYE tablolarıdır. Pnömoni, bronşit ve akut bronşiolit de en sık görülen alt solunum yolu enfeksiyonlarını olușturmaktadır. Gelişmekte olan ülkelerin çoğunda olduğu gibi ülkemizde de 0-4 yaş arası çocukların en sık ölüm nedeni solunum yolu enfeksiyonlarıdır $(3,4)$.

Birçok akut ve kronik hastalıkta alternatif tedavi yöntemleri uygulanmaktadır. Sık görülen solunum yolu enfeksiyonlarında tıp dışı alternatif uygulamaların kullanıldığı birçok çalışmada gösterilmiştir $(5,6)$.

Bu çalışmada, solunum yolu enfeksiyonu şikâyetleri ile hastanemize başvuran çocukların ailelerinin çocuklarında kullandığı alternatif yöntemler, bu yöntemlerin sıklığı ve ailelerin bu konudaki bilgi ve tutumları araştırımıştır.

\section{Gereç ve Yöntem}

Ekim 2011-Şubat 2012 tarihleri arasında Çanakkale Onsekiz Mart Üniversitesi Araştırma ve Uygulama Hastanesi Çocuk Sağlığı ve Hastalıkları Genel Polikliniğine; ateş, öksürük, boğaz ağrısı, hırıltı gibi şikâyetlerle başvurup üst veya alt solunum yolu enfeksiyonu tanısı alan çocukların anneleri çalışma gurubunu oluşturdu. Hazırlanan, kişisel bilgiler ve alternatif tıp uygulamaları ile ilgili sorulardan oluşan anket formları araştırmaya katımayı kabul eden ailelerle araştırmacılar tarafından yüz yüze görüşülerek dolduruldu. Onam vermeyen aileler ve çocukları çalışmaya dâhil edilmedi.
Ailelerin hangi durumlarda ve hangi sıklıkta tıp dışı uygulamaları kullandıkları, kimlerden bilgi aldıkları ve başkalarına bu uygulamalarla ilgili yansıttıkları veriler araştırmacılar tarafından doldurulan anket formlarından SPSS 20 istatistik programına yüklenerek istatistiksel analizler (frekans, \% oran ve ki kare) yapıldı. $p<0,05$ anlamlı olarak kabul edildi.

\section{Bulgular}

Çalışmaya 214 solunum yolu enfeksiyonu geçiren çocuk ve anneleri alındı. Çocukların 115'i erkek $(\% 53,7)$ ve 99'u $(\% 46,3)$ kızdı. Çocukların ortalama yaşı 7,1 1 3,6 (1-16) idi. Çalışmaya dâhil edilen annelerin \%1,4'ü okuryazar değilken, \%28,0'i üniversite mezunu idi (Tablo 1). Ayrıca annelerin \%62,6'sı ev hanımı, \%2,8'i sağlık çalışanı ve \%34,6‘sı da diğer meslek gruplarındandı. Annelerin ortalama yaşı $34,2 \pm 6,2(22-58)$ idi.

Ebeveynlere çocuklarında üst solum yolu enfeksiyonu tedavisinde ilaç dışı uygulamalardan faydalanıp faydalanmadıklarını sorduğumuzda, \%6,3'ü asla uygulamadığını belirtirken, \%39'u bazen, \%33,7'si çoğunlukla, \%20'si nadiren, \%1'i de her zaman bu uygulamalara başvurduklarını belirtti.

Ailelere ilaç dışı uygulamaları ne zaman yaptığı sorulduğunda, \%62,7'si ilaç tedavisinden önce, \%28,7'si ilaçlarla birlikte uyguladıklarını bildirirken, ilaçlara cevap alınamadığında uygulayanların oranı \%6,7'si idi. Bu yöntemleri hiç uygulamadıklarını belirtenlerin oranı ise $\% 1,9$ olarak bulundu.

Ateşi düşürmek için ve öksürüğü azaltmak veya kesmek için yapılan uygulamalar Tablo 2 ve Tablo 3'te özetlenmiştir. Ateşi düşürmek için doğru uygulama olarak kabul edilen ılık duş uygulamasının oranı \%48,1 iken bunun dışındaki yanlış uygulamalar \%51,9 olarak bulundu.

Yapılan uygulamalar ile ilgili ailelerin bilgi kaynaklarının, akrabalar $(\% 35,4)$, aile bireyleri (\%34), doktor (\%11),

\begin{tabular}{|l|c|}
\hline \multicolumn{2}{|l|}{ Tablo 1. Çalışmaya katılan annelerin eğitim durumları } \\
\hline Eğitim durumu & $\mathbf{n}(\%)$ \\
\hline Illkokul & $96(44,9)$ \\
\hline Ortaokul & $31(14,5)$ \\
\hline Lise & $24(11,2)$ \\
\hline Üniversite & $60(28,0)$ \\
\hline Okur-yazar değil & $3(1,4)$ \\
\hline
\end{tabular}


televizyon-radyo $(\% 9,6)$, hemşire vb. sağlık çalışanı $(\% 2,9)$, arkadaşlar $(\% 1,9)$, internet $(\% 1,4)$ ve eczaneler $(\% 0,5)$ olduğu saptandı.

Ailelere "uygulamalardan fayda gördünüz mü?" diye sorulduğunda, hiç fayda görmedim diyenler $\% 5,6$, biraz diyenler $\% 14,4$, orta seviyede fayda gördüğünü söyleyenler $\% 26,8$, iyi faydalandığını belirtenler $\% 49,3$, çok fayda gördüğünü söyleyenler ise \%3,8 olarak bulundu.

"Uygulamaların zararı olabilir mi?" diye sorulduğunda, hiç zararı olmadığını söyleyen $\% 70,4$, biraz zararlı olabileceğini söyleyen $\% 19,9$, orta seviyede zararıdır diyen $\% 5,8$, çok zararlıdır diyenler de $\% 3,9^{\prime}$ du.

Aynı yöntemleri \%92,8'i kendisine ve eşine de uyguladığını belirtirken, \%7,2'si ne kendisine ne de eşine uygulamıştı.

"Uygulamaları tekrar yapar mısınız?" diye sorulduğunda, evet diyenler $\% 89,9$, hayır diyenler ise $\% 10,1$ olarak bulundu.

Ebeveynlerin \%87,5'i bu uygulamaları başkalarına da tavsiye ettiklerini belirtirken, \%12,5'i tavsiye etmeyeceklerini belirtti.

Bu ve benzeri uygulamalarla ilgili olarak bilgi edinilmek istenen kaynaklar Tablo 4'te verilmiştir.

Eğitim durumu ile ilaç dışı uygulama sıkığı arasındaki ilişki istatistiksel anlamlı $(p<0,001)$ bulunmuş olup, eğitim seviyesi arttıkça ilaç dışı uygulamalardan uzaklaşıldığı görülmektedir. Ilaç dışı uygulamayı yapma zamanı ve eğitim durumu arasında ilişkiye bakıldığında da istatistiksel olarak anlamlı fark vardı $(p<0,01)$.

Çalışmamızda meslek grubu ile ilaç dışı uygulama sıklığı arasında istatistiksel anlamlı fark bulunmadı. $(p=0,23)$.

İlaç dışı uygulama ile ilgili bilgi kaynağı okur-yazar olmayan ve ilkokul mezunları için daha çok aile yakınları

Tabıo 2. Ateşi düşürmek için en sık yapılan ilaç dışı uygulamalar

\begin{tabular}{|l|c|}
\hline Sirkeli su & $\% 16,3$ \\
\hline Soğuk suyla silmek & $\% 28,4$ \\
\hline llık duş & $\% 48,1$ \\
\hline Vücuda buz sürmek & $\% 1,4$ \\
\hline
\end{tabular}

Tablo 3. Öksürüğü azaltmak veya kesmek için en sık yapılan ilaç dışı uygulamalar

\begin{tabular}{|l|l|}
\hline Sade bal vermek & $\% 30,6$ \\
\hline Buhar uygulamak & $\% 14,4$ \\
\hline Zencefilli bal vermek & $\% 6,7$ \\
\hline Pekmez vermek & $\% 5,7$ \\
\hline Karaturp ile bal karıştııр vermek & $\% 5,3$ \\
\hline Sadece vücuda bal sürmek & $\% 2,4$ \\
\hline Birden fazla uygulama yapmak & $\% 26,8$ \\
\hline
\end{tabular}

iken, eğitim durumu arttıkça bu kaynağın doktor, sağlık çalışanı ve internet şeklinde değiştiği görüldü $(p<0,01)$.

İlaç dışı uygulamanın zararları olabileceği ile ilgili görüş ve eğitim düzeyi arasında anlamlı ilişki bulunmadı $(p=0,17)$.

Ayrıca bilgi alınmak istenen kaynak ile eğitim durumu arasında istatistiksel anlamlı fark $(p=0,17)$ yoktu ve en sık bilgi alınmak istenen kaynak doktorlardı.

\section{Tartışma}

Yapılan çalışmalarda alternatif tedavi uygulamalarının son yıllarda tüm dünyada artış gösterdiği bilinmektedir $(7,8)$. Tabii ki bu artışın ülkemizde de olması kaçınılmazdır (9). Yapılan çalışmalarda Türkiye genelinde alternatif tedavi yöntemlerini kullanım oranı \%36-70 olarak saptanmıştır $(10,11)$.

Ülkemizde yapılmış alternatif tıp uygulamalarına bakıldığında çeşitli farklılıklar vardır. En belirgin farkılıklar olarak kullanılan yöntemler, çalışma grupları arası farklar ve çalışma yapılan bölgeler belirtilebilir. Gözüm ve arkadaşlarının Doğu Anadolu Bölgesi'nde yaptığı çalışmada (12) ilaç dışı alternatif tedavi kullanımının eğitim düzeyi düşük olanlarda ve özellikle kadınlarda daha yüksek olduğu gösterilmiştir. Ceylan ve arkadaşlarının, Iç Anadolu Bölgesi'nde yaptığı çalışmada da eğitim düzeyi açısından benzer sonuçlar bulunmuştur (13). Yavuz ve arkadaşlarının (14) Ege Bölgesinde yaptığı çalışmada ise alternatif tedavilerin yüksek eğitimli ve iyi ekonomik düzeyi olan kadınlar tarafından daha fazla kullanıldığı bulunmuștur. Bülbül ve arkadaşlarının (15) yine Iç Anadolu Bölgesinde yaptığı çalışmada ise çalışmayan ve lise mezunu anne ve babalar arasında alternatif tedavi kullanımının sık olduğu gösterilmiştir. Bu çalışmada da, Doğu ve Iç Anadolu Bölgelerindeki çalışmalara benzer şekilde eğitim düzeyi düşük kişilerde daha fazla alternatif tedavilere eğilim olduğu görüldü.

Bozkaya ve arkadaşlarının (16) çalışmasında alternatif tedavilerin kişilerin kazancı ne kadar olursa olsun kolay

\begin{tabular}{|c|c|}
\hline Doktor & $\% 82,1$ \\
\hline Televizyon-radyo & $\% 4,3$ \\
\hline Aile bireyleri & $\% 3,9$ \\
\hline Hemşire vb. sağlık çalışanı & $\% 2,4$ \\
\hline Akrabalar & $\% 1,9$ \\
\hline Dergi-gazete & $\% 1,9$ \\
\hline Internet & $\% 1,4$ \\
\hline Eczane & $\% 0,5$ \\
\hline
\end{tabular}


erişilebilirlik açısından seçilmekte olduğu ve sıklıkla tek başına değil, tıbbi tedavi yöntemlerine yardımcı olarak kullanıldığı gösterilmiştir. Bu çalışmada ise ailelerin alternatif tedavi uygulamalarını ilaç tedavisi ile birlikte değil de \%62,7 gibi sıklıkla ilaç tedavisinden önce yaptıklarını görüldü.

Araz ve arkadaşlarının çalışmasında (17) alternatif tedavi yöntemlerinde bilgi kaynakları olarak \%76,6 ile TV-radyo bulunmuştur. Bozkaya ve arkadaşlarının çalışmasında ise kişiler alternatif tedavi yöntemlerini $\% 68,9$ gibi bir sıklıkla aile büyüklerinden öğrendiğini söylemişlerdir (16). Bu çalışmada da benzer şekilde bilgileri edinme kaynağı olarak \%69,4 gibi bir sıklıkla aile bireyleri ve akrabaların olduğu bulunmuştur. Bozkaya ve ark. çalışmalarında bilgi kaynağı olarak basın-yayından yararlananların \%63'ünün kullandığı yöntemi başkalarına da tavsiye ettiğini bulmuşlardır. Ayrıca bu verileri de sağlık konusunda basın-yayın kuruluşlarının çok etkili olduğunun kanıtı olarak sunmuşlardır (16). Sunulan çalışmada ise ailelerin yaptıkları uygulamaları başkalarına da tavsiye etme oranı oldukça yüksek $(\% 87,5)$ bulundu. Bu da alternatif tedavi uygulamaları konusunda insanların doğru bilgilendirilmeye ihtiyacı olduğunu düşündürmektedir.

Yurt içi ve yurt dışında yapılmış çalışmalarda kronik hastalığı olan kişilerin alternatif tedavi kullanma sıkığının normal popülâsyondan daha yüksek olduğu bulunmuştur. Aynı yayınlarda kullanıcılar alternatif tedavilerin rutin tıp uygulamalarından daha başarılı olabileceğini düşündüklerini bildirilmişlerdir (18-20). Bu çalışma kronik hastalığı olanlarda yapılmamasına rağmen hasta grubumuzun da alternatif yöntemleri ilaç öncesi ve ilaçlarla birlikte \%91,4 gibi sıklıkta kullanması, alternatif tedavilere ilaçlardan daha çok güvenildiğini düşündürmektedir. Çocukluk çağı alternatif tedavi uygulamaları ile ilgili yapılan çalışmaların çoğunun kronik hastalığı olan çocuklarda yapılmış olduğu görülmektedir (11). Bu çalışma ise akut hastalığı olan çocuklarda yapılmış olup, sonuçları bu yönüyle de anlamlıdır.

Bu çalışmada da görüldüğü gibi çocukluk çağı alternatif tedavi uygulamaları genellikle çocukların ailelerine bağlıdır. Ebeveynlerin çoğu kendilerine uyguladıkları tedavileri çocuklarına da uygulamaktadırlar. Çalışmamızda da katılımcıların \%87,5'i kendi uygulamalarını çocuklarına da uyguladıklarını ve hatta başka ailelere de tavsiye ettiklerini belirtmişlerdir.

Özet olarak bu çalışmada ailelerin \%82,1 gibi yüksek bir oranda doktorlarından bilgi edinmek istedikleri görülmüştür. Elde edilen bu bulgu doğrultusunda çocuk sağlığı ve hastalıkları hekimleri ve hemşirelerinin bu yöntemler hakkında bilgi edinip ailelere doğru yaklaşımlar hakkında yardımcı olmaları gerektiği sonucuna varılmıştır.

\section{Kaynaklar}

1. Madsen H, Andersen S, Gaardskaer Nielsen R, Dolmer BS, Host A, Damkier A. Use of complementary/alternative medicine among paediatric patients. Eur J Pediatr 2003;162:334-41.

2. Davis MP, Darden PM. Use of complementary and alternative medicine by children in the United States. Arch Pediatr Adolesc Med 2003;157:393-6.

3. Çocuk Enfeksiyon Hastalıkları Derneği: Çocuklarda üst solunum yolu enfeksiyonları, Çocuk Enfeksiyon Hastalıkları Derneği Yayınları; Istanbul, 2002; s. 3-76.

4. Ertuğrul T, Tanman B. Solunum sistemi infeksiyonları. Olcay N, Ertuğrul T. Pediatri Cilt 2, Istanbul, Nobel Tıp Kitapevleri; 2002. s. 870-916.

5. Pitetti R, Singh S, Hornyak D, Garcia SE, Herr S. Complementary and alternative medicine use in children. Ped Emerg Care 2001;17:165-9.

6. Robinson N, Blair M, Lorenc A, Gully N, Fox P, Mitchell K. Complementary medicine use in multi-ethnic paediatric outpatients. Complement Ther Clin Pract 2008;14:17-24.

7. Linde K, Jonas WB, Melchart D, Willich S. The methodological quality of randomized controlled trials of homeopathy, herbal medicines and acupuncture. Int J Epidemiol 2001;30:526-31.

8. Steurer-Stey C, Russi E. Complementary and alternative medicine in asthma - do they work? Swiss Med Wkly 2002;132:338-44.

9. Orhan F, Sekerel BE, Kocabaş CN, Saçkesen C, Adalıoğlu G, Tuncer $A$. Complementary and alternative medicine in children with asthma. Ann Allergy Asthma Immunol 2003;90:611-15.

10. Tan M, Uzun O, Akçay F. Trends in complementary and alternative medicine in eastern Turkey. J Altern Complement Med 2004;10:861-5.

11. Karayağız Muslu G, Öztürk C. Tamamlayıcı ve alternatif tedaviler ve çocuklarda kullanımı. Çocuk Sağlığı ve Hastalıkları Dergisi 2008;51:62-7.

12. Gözüm S, Tezel $A$, Koç $M$. Complementary alternative treatments used by patients with cancer in eastern Turkey. Cancer Nurs 2003;26:230-6.

13. Ceylan S, Hamzaoğlu O, Kömürcü S, Beyan C, Yalçin A. Survey of the use of complementary and alternative medicine among Turkish cancer patients. Complement Ther Med 2002;10:94-9.

14. Yavuz M, Ilçe A, Kaymakçı Ş, Bildik G, Dıramalı A. Meme kanserli hastaların tamamlayıcı ve alternatif tedavi yöntemlerini kullanma durumlarının incelenmesi. Turkiye Klinikleri J Med Sci 2007;27:680-6.

15. Bülbül SH, Turgut M, Köylüoğlu S. Çocuklarda tıp dışı alternatif uygulamalar konusunda ailelerin görüşleri. Çocuk Sağlığı ve Hastalkkları Dergisi 2009;52:195-202.

16. Bozkaya ÖG, Akgün I, Birgi E, Çinkoğlu A, Gög K, Karadeniz $\mathrm{K}$. Anne babaların çocuklarında uyguladıkları alternatif tıp yöntemleri. DEÜ Tıp Fakültesi Dergisi 2008;22:129-35.

17. Araz A, Harlak H, Meşe G. Health behaviors and alternative medicine use. TAF Prev Med Bull 2007;6:112-22.

18. Eisenberg DM, Davis RB, Ettner SL, Appel S, Wilkey S, Van Rompay $\mathrm{M}$ et al. Trends in alternative medicine use in the United States 1990-1997. JAMA 1998;280:1569-75.

19. Kurt E, Bavbek S, Pasaoglu G, Abadoglu O, Misirligil Z. Use of alternative medicine by allergic patients in Turkey. Allergol Immunopathol (Madr) 2004;32:289-94.

20. Hassed C. An integrative approach to asthma. Aust Fam Physician 2005;34:573-6. 